\title{
Screw Expander for Energy Production in Natural Gas Pressure Reduction and Mesurement Stations
}

\author{
João Reis, Jorge Mendonça e Costa and Nuno Soares Domingues* \\ Departamento de Engenharia Mecânica, Instituto Superior de Engenharia de Lisboa, Portugal
}

Submission: February 27, 2018; Published: March 19, 2018

*Corresponding author: Nuno Soares Domingues, Departamento de Engenharia Mecânica, Instituto Superior de Engenharia de Lisboa, Lisboa, Portugal, Email: nndomingues@gmail.com

Abstract

The current energy paradigm requires a strong need not only to use sustainable energy sources but also to make better use of existing energy resources. This last category, represented, mainly, by fossil fuels, needs new and better practices where they are fully used. Within fossil fuels, natural gas has a relevant role, mainly because of its low levels of pollutant emissions, with respect to other fuels, and its abundance in nature and in coping with consumption variation. However, this resource is not fully utilized, since during natural gas pressure reduction processes a great amount of energy is wasted that otherwise could be harnessed and converted into electrical energy. The aim of this paper is to qualitatively define and evaluate the performance of a screw-type expansion machine to be installed in natural gas pressure reduction and measurement stations (GPRMS) in order to take advantage of the higher enthalpy level available in the gas in order to generate electrical energy during the expansion process. After a definition of the expander, it is intended to discuss if it exceeds the classical solution corresponding to a conventional turbine for the purpose of energy generation, allowing an effective response to the strong daily variation of flow in the gas line.

Keywords: Pressure reduction; Natural gas; Expansion; Screw expander; Energy

\section{Introduction}

The current process of natural gas pressure reduction leads to a loss of the gas total available energy, transforming its harvestable portion into heat, during the throttling process in the regulator valve used for the pressure reduction purpose. Using an expander, instead of a valve, induces a distinct pressure reduction process which leads to work production through the expander by means of a change in the flow's enthalpy, instead of a change in the flow's entropy as occurs in a valve throttling process [1-3].

Up till now the use of a turbine as the expander is the most common solution, if not the only one. This solution, as good as it may sound, presents its fair share of downsides resulting in a small application throughout the gas pressure reduction and measurement stations (from now on called simply by their acronym, GPRMS) worldwide. These downsides are mainly economic, and even the ones regarding the process or the expander, show themselves, ultimately, as economic. Therefore, in order to suppress some of the main disadvantages of the conventional turbine, we can adopt another machine, in an effort to completely harness natural gas pressure energy, thus rendering it more profitable and consequently increase its worldwide use. Efforts in study and implementation of screw machines as expanders may become a reality, provided that these machines successfully surpass the disadvantages inherent to a turbine $[4,5]$.

\section{Literature Review}

Literature about screw machines is very scarce, although some interest in these machines is starting to show. This is mostly due to the fact that until now most of the proprietor knowledge and data about these machines is out of the scope of academic institutions, worldwide, that do not promote their understanding and development. Additionally, building on the few published studies and information to this equipment, a big portion of printed material is not readily available in English, according to [6].

Despite the obstacles presented in the last paragraph there are still some insightful references about screw machines and the application of screw expanders in Organic Rankine Cycles (ORC's). In these fields of study, we would like to highlight two main authors, namely Ian Smith and Nikola Stosic whose work consists in a substantial amount of publications that provide ground knowledge to almost all the remaining authors that tackle this subject.

References [1] and [5] tackle some aspects of gas expansion power production and the main aspects to take into account, 
though referring to turbines instead of screw expanders. Reference [2], shows an early work regarding screw expanders and its use in ORC cycles, by the main authors above referred.

Still regarding the two mentioned authors, references [4] and [6] show recent work, namely a paper regarding turbine vs screw expanders performance, again, in ORC cycles and their off-design performances, and a book encompassing a comprehensive mathematical approach to screw machines in general, respectively. This last one, aside for the authors life work, is personally considered as a huge contribution to screw machines public understanding and development, enabling new studies and publications about this subject. Last, but not least, reference [3] is a very insightful and enlightening work regarding the evolution of screw machines, mostly screw compressors, dwelling on their specific aspects and characteristics.

\section{Screw Machines Technological Review}

The performance of screw machines is highly connected to their own profiles and clearances, which combined define the machine's lobes. The lobes and the casing contain the working chambers- of variable volume-in this kind of machine. Due to its working process (and screws rotation), lobes create an unsteady volume throughout one screw rotation.

For this kind of machines, efficiency is directly affected by internal leakages (whether from lobe infiltrations, or from lobe leakages), as can be deduced from equation (1), (2) and (3), hence the work done per angle of rotation is defined not including mass flow, but discretizing mass flow by what comes in and out of the lobe, during the process, accounting for lobe leakages and infiltrations.

Before explaining what has permitted this kind of machines to flourish, there is a need to explain some of their most important aspects and details that influence their best performance. The first thing that has to be acknowledged is that each application has its own profile, meaning that not all natural gas expansions, regardless of the conditions use only one suitable profile, designed specifically to expand natural gas.

When referring to profile definition it is important to keep in mind that the global machine's profile accounts for the combination of male and female lobe combination and male and female rotor profile, thus leading to suction and discharge ports' profiles.

The profile definition must be carefully planned and all data regarding the process, must be well known for the profile is directly bound to the contact force between rotors, smoothness of torque transfer, lubricant film formation capacity, sealing line length, lobe volume and rotor manufacturing reproducibility.

As previously mentioned, clearances, of all physical features, are those which influence the process behavior the most, as clearances allow paths for leakages which proved to be directly linked to efficiency.

Despite allowing leakages, clearances are necessary, namely nominal clearances at rest state (or 'at rest' leakages as stated in [3]). They prevent contact between rotors thus avoiding damage to themselves and the machine. On the one hand these clearances must be large enough to prevent harmful contact such as collisions or slide between rotors, promoting erosion, and on the other hand must be small enough to keep leakages to a minimum, since they affect efficiency.

Additionally nominal clearances must be considered to account for manufacturing imperfections, machining tolerances and deflections originating from various kinds of loads. These loads include pressure loads derived from the thermodynamic process occurring, causing rotors and bearings deflections, and thermal loads leading to rotors and casing deflections. These combined effects drastically change nominal clearances during the machine's operation. Keeping in mind what was stated about clearances, some rotor profiles may have complex defining curves, therefore the respect for machining tolerances, and accounting, for obvious machining imperfections can impair replication of the same profile in a large scale.

One of the main reasons why there is a growth in the uptake of screw machines, namely compressor screw machines, is the improvement in manufacturing technologies and tools. This improvement is responsible for large scale manufacturing of more complex and tolerance complying rotors and components for screw machines, in a more efficient and not so expensive way (Figure 1).

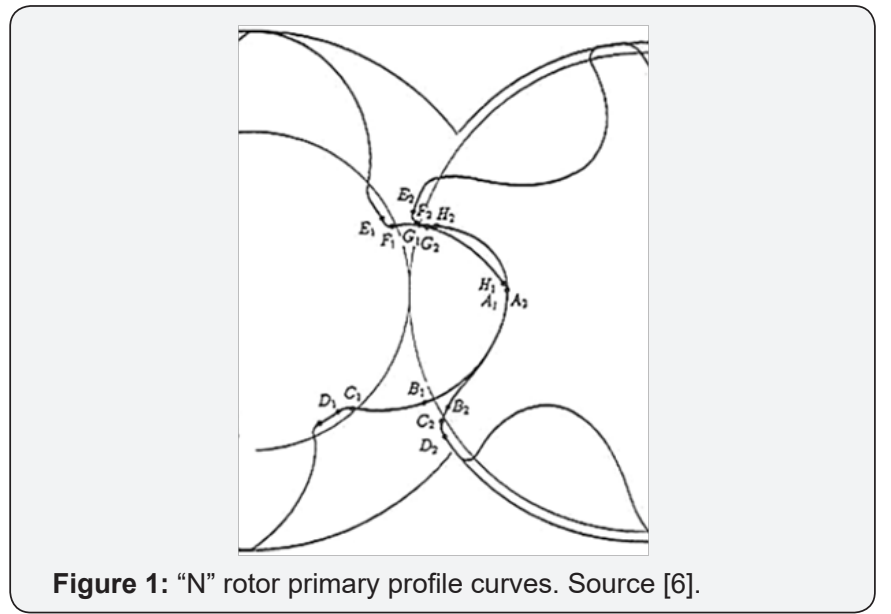

Still regarding clearances, and make no mistake, all advances leading to screw machines growth and improvement end up in enhancing profile suitability and therefore clearances upgrade. The clearance between rotors should be as uniform as possible so the contact pattern between rotors can be as even as possible enabling good torque transfer with the least transmission error and energy losses thus allowing for minor and even rotor erosion, low levels of vibrations, or noise, leading to a long life 
for screw machines internal components and preventing for uneven leakage paths along the screws which will surely affect machine performance along its length.

This last aim was achieved, aside from better component manufacturing, due to new technologies enhanced with bearings evolution. Despite bearings capacity for absorbing loads, their concentricity tolerances improved the clearance between rotors because manufacturing technologies presently allow more rigorous and tight tolerances (Figure 2). Therefore mass production of new, more efficient and reliable screw machines, conquered a new level of relevance in many industrial applications today.

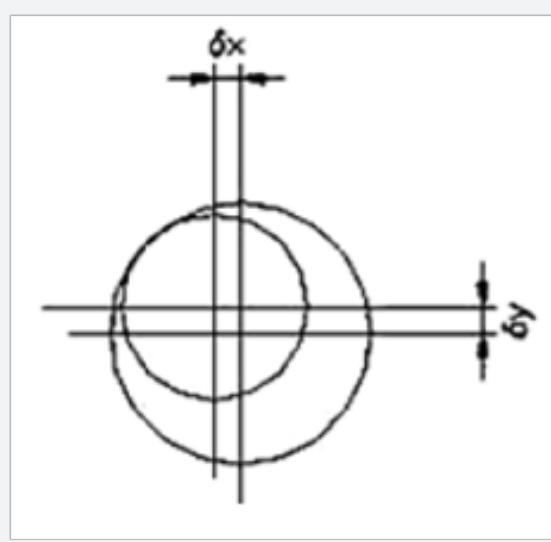

Figure 2: Bearing displacement, caused by rotor loads. Source [6].

\section{Working Principle and Off-Design Operation}

Screw expanders are volumetric machines, obeying to some specific behaviors, yet to be explained ahead in this section which are characteristic to this machine's group. Assuming a one-dimensional flow through the machine it is possible to find, for a non-steady flow, the variation of internal energy, in each lobe of the machine and for the rotor angular position.

$$
\begin{gathered}
\omega \frac{d u}{d \theta}=m_{-} \text {inh_in }-m_{-} \text {outh_out }+Q-\omega p \frac{d v}{d \theta} \\
m_{-} \text {in }=m_{-}(\text {sus. })+m_{-}(\text {inf } .) \\
m_{-} \text {out }=m_{-}(\text {dis. })+m_{-}(\text {leak } .)
\end{gathered}
$$

In order to continue further in this section, there is a need to explain a particular situation occurring in screw machines. Therefore, it is important to briefly discuss rotation speed and its effects on screw machines efficiencies and work produced. As a volumetric machine, the increase in rotation speed means that mass flow increases as well but does not imply any changes in the process. This means that expansion process will stay the same regardless of rotor speed thus delivering the same amount of energy per unit mass. Rotation speed influences, though, the rate of mass transfer between consecutive lobes of the machine, therefore leakages and infiltrations. This translates in machine efficiency variation as leakages imply losses in the process that should be as low as possible. Higher speeds leave less time to allow leakages to happen, opposite to lower speeds which leave more time for mass to exchange between lobes.

Rotation speed can, therefore, be related to mass flow through the following expression.

$$
\omega \frac{(d m)}{d \theta}=m_{-} \text {inh_in }-m_{-} \text {outh_out }
$$

With equation (4) and what was mentioned before, about rotation speed only affecting the volume transported through the machine, it is easy to conclude that when mass flow varies, the machine speed varies likewise. Now it becomes important to mention the main advantage to explore in screw expanders relatively to turbines regarding to this relation.

After a careful analysis of equation (1), it is possible to develop some interesting conclusions. Firstly, let's divide the equation's right hand side in three main terms. From left to right, there are three main terms, the energy term, the heat term and the "dynamic term" as it is going to be addressed in this paper. Secondly, let's assume that the heat, per unit mass, released during the process only regards machine's inlet and outlet conditions, not being influenced, in any way, by rotation speed.

Thirdly, being a volumetric machine, rotation speed has no influence in the process other than the volume transported through the machine. That being said, when the flow through the system varies with respect to the nominal design conditions, the energy term varies as well, thus influencing the work done by the machine. Yet, let's say, if the flow rate lowers, regarding nominal conditions, rotor speed can lower since the need for flow (now introducing natural gas expansion cases) on the exiting end of the expander is lower.

This effect shows a kind of auto-compensation effect, once the energy term decreases with a lower mass flow rate, on the other hand the negative effect caused by the dynamic term is attenuated with the rotation speed adjustment, contributing to a more stable work production. Therefore, it can be expected that screw expanders are steadier machines regarding to work produced and operating process.

\section{Screw Expanders in Natural Gas GPRMS}

Aside from the classical throttling valve solution for natural gas pressure reduction, work can be extracted from an expander due to enthalpic variation, as characterized in Figures $3 \& 4$. In regard to expanders there are two options, namely a radial turbine or the screw expander.

As far as turbine solution goes there are only a few cost efficient stations, mainly due to high investment and maintenance costs, long down times due to natural gas required flow fluctuations with respect to nominal flow and a stronger need for pre-heating of natural gas, than the classical solution, due to higher temperature differences due to the nature of the process, yet again implicitly shown in Figures $3 \& 4$. 

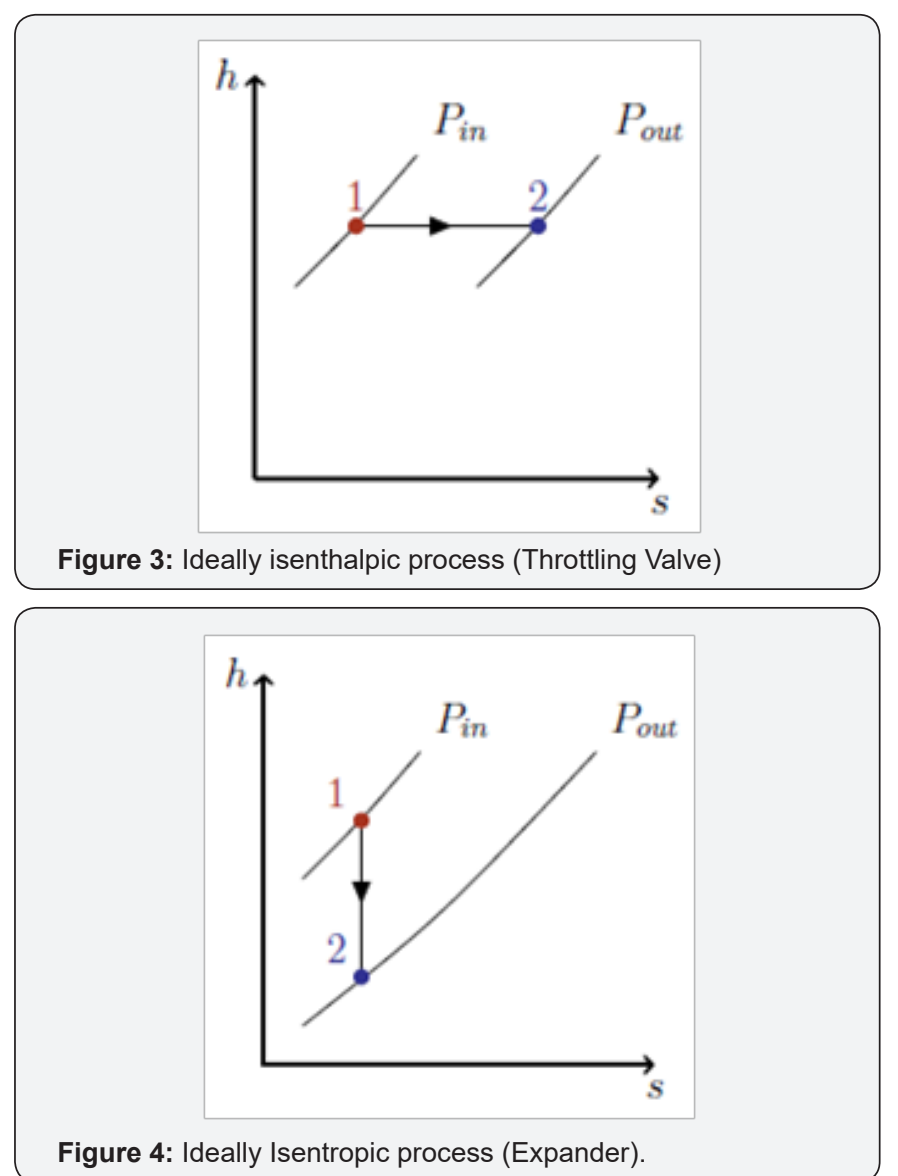

Despite what was said the main cause for turbines economic unfeasibility stems from the turbine's weak resistance to flow fluctuations, since the turbine's peak work production occurs for nominal design conditions, followed, by a sharp drop for offdesign conditions. Furthermore when the flow is considerably lower than its nominal value, the equipment must stop, or if the flow is higher than its nominal value there must be a bypass with the classical valve. This situation calls for the classical solution, of the throttle valve, for the natural gas expansion, meaning long stop periods which are obviously disadvantageous both economically and energetically.

Alternatively to the turbine, the screw expander, though complex, presents some advantages which might mean a huge advantage and better and wider application and therefore a full replacement on both valve and turbine solutions.

Regarding to flow off-design conditions, these machines can cope with flow variations using their own capacity to adapt their rotation speed to instant flow variations. This speed adjustment is exactly the one explained in the previous section, in which the range of flow worth expanding through the machine is wider than in the case of a turbine. Screw expanders rotation speed, is only limited by two conditions, one defining a minimum machine's velocity, where leakages attain a maximum acceptable level, another defining its maximum velocity, where rotor tip speed is limited, by fluid mechanics, to sonic velocity. Therefore these machines range might be defined by these two velocity conditions.

Another huge advantage of screw machines is their compatibility with two-phase flow processes. This is highly advantageous in natural gas expansion, where water vapour tends to condensate, setting all the requirements for hydrate formation, which is a problem for turbines and piping in general, since hydrates destroy, by erosion, turbine blades, and/or deposit, creating piping obstruction. This two or multiphase work capacity allows for low or no need for pre-heating, or even a small reheating, since condensation is now allowed, reducing some boiler or CHP costs, or even widening the range of nearby exhaust gases or waste heat from nearby industries or applications that can be exploited free of charge. At the expander's exit might even be possible to purge some of the natural gas impurities condensed in this way.

Finally, screw expanders are dynamically well balanced machines since all their moving parts are rotational leading to minor vibrations and noise. Since these machines comprise a relatively low amount of parts, and the mean time between failure (MTBF) is directly linked to the machine's number of parts, screw expanders are globally more reliable machines. Additionally since screw machines rotors do not touch, or maintain long periods of contact, rotor erosion is very low. All these factors allow screw machines to have a long life period relying only on basic and therefore cheaper maintenance interventions.

\section{Conclusion and Further Work}

Screw machines are relatively recent in industry and energy applications, this demands further work to be done in order to openly understand and develop this new equipment that shows some advantages with respect to conventional expanders.

These machines can withstand a process involving two-phase flow and even flow fluctuations maintaining, to some extent, a steady work delivery. Furthermore screw expanders present a very low maintenance need keeping their operational costs to a minimum. In sum, not only screw expanders are reliable and low operational cost machines, they also maintain a steady production, contrary to regular turbines, therefore increasing energy production and profit.

As future work goes, the next step has to include a mathematical definition for the machine's profile to be solved simultaneously with a set of fluid mechanics and thermodynamics equations, like equations (1), for example, since profile and process optimization lead to a long and complex numerical study. This study will prove screw expanders behavior through flow fluctuations and frame a scenario of what to expect from screw expanders work production in natural gas expansion process.

\section{References}

1. Lehman B, Worrel E (2001) Electricity production from natural gas pressure recovery using expansion turbines. ACEEE Summer Study on Energy Efficiency in Industry, pp. 43-54. 


\section{Recent Advances in Petrochemical Science}

2. Smith IK, Stosic N, Aldis CA (1994) Lysholm machines as two-phase expanders. International Compressor Engineering Conference 975:6166.

3. Flemming JS, Tang Y, Cook G (1998) The twin helical screw compressor Pat 1: development, application and competitive position. I Mech E 212(5): 355-367.

4. Read M, Smith IK, Stosic N, Kovacevic A (2016) Comparison of organic Rankine cycle systems under varying conditions using turbine and twin-screw expanders. Energies 9(8): 614.
5. Rahman MM (2010) Power generation from pressure reduction in the natural gas supply chain in Bangladesh. Journal of Mechanical Engineering 41(2): 89-95.

6. Stosic N, Smith IK, Kovacevic A (2005) Screw compressors: Mathematical Modelling and Performance Calculation, SpringerVerlag, Netherlands.

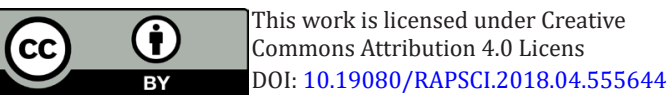

\section{Your next submission with Juniper Publishers will reach you the below assets}

- Quality Editorial service

- Swift Peer Review

- Reprints availability

- E-prints Service

- Manuscript Podcast for convenient understanding

- Global attainment for your research

- Manuscript accessibility in different formats

( Pdf, E-pub, Full Text, Audio)

- Unceasing customer service

Track the below URL for one-step submission https://juniperpublishers.com/online-submission.php 